\title{
Testosterone Concentration and Testicular Histomorphology of Rats Exposed to Hippocratea Africana Root Bark Extract
}

\author{
* Jessie Idongesit Ndem, Victor Eno Johnson \\ (Department of Biochemistry, Faculty of Basic Medical Sciences, University of Uyo, Nigeria) \\ "Correspondence Author: jessndem@yahoo.com
}

\begin{abstract}
Malaria is a scourge of the tropical region of the world, affecting mostly the poor who cannot afford the World Health Organisation (WHO) recommended artemisinin combination therapy. This results in the continuous reliance on herbal remedies for the treatment of the disease. Hippocratea africana is one of the herbs used traditionally for the treatment of malaria in South Eastern region of Nigeria. Testosterone concentration and testicular histomorphology were assayed to assess the effect of the herb on male reproductive function. Experimental groups were formed as follows; control group 1 administered $1 \mathrm{ml}$ of distilled water and test groups II, II and IV administered 100, 200, and $300 \mathrm{mg} / \mathrm{kg}$ body weight of the root bark extract. One-way analysis of variance (ANOVA) and Student's Test (t- test) were used for statistical analyses. The result showed significant $(p<0.05)$ increase in the concentration of testosterone in all the test groups compared with the control in a dose dependent manner. There was no evidence of pathology on the photomicrographs of the testes of all the test groups compared with the control. The results show that the herb did not cause lesions and degenerative changes in the testes and improved testicular steriodogenesis and so maybe safe for its use as an antiplasmodial agent.
\end{abstract}

Keywords: Hippocratea africana, Malaria, Testosterone, Testes, Histomorphology

\section{Introduction}

Malaria is one of the most serious health problems facing the world today. Recent reports have stated that over 214 million cases of malaria occur worldwide resulting in an estimated 438,000 deaths, $90 \%$ of which occurs in Africa, particularly amongst pregnant women and children. ${ }^{1}$ Malaria is commonly associated with poverty and has a major negative effect on economic development. The treatment of malaria has faced several challenges due to the affordability, availability and efficacy of antimalarial drugs. ${ }^{2}$ Development of resistance to certain plasmodium strains has also made different classes of drugs used for the treatment of the disease in the past to be ineffective and almost useless in some areas. ${ }^{3}$ Some of these drugs include chloroquine and fansidar. ${ }^{4}$ The prevalence of malaria has resulted in indiscriminate use, abuse and patient's non-compliance to therapeutic regimens. Cytotoxicity and side effects of antimalarial drugs also contribute to these challenges in the treatment of malaria ${ }^{5}$.

Several antimalarial drugs and herbs have been studied to evaluate their toxicological effects in reproductive function. ${ }^{6,7}$ Many antimalarial drugs have been associated with male reproductive dysfunction. For example, P-Alaxin has been reported to significantly reduce the testosterone level in male rats. ${ }^{8}$ There is a report that oral artemisinin derivative, artemether, caused a significant reduction in progressive sperm motility, viability, sperm count and serum testosterone levels in a dose dependent fashion during an acute administration of the drug in male rats. ${ }^{9}$ Chloroquine has been reported to reduce sperm motility and hence, fertility, by a reduction in the average number of fetuses, of cohabited female rats. ${ }^{10}$ Furthermore, a study on potential effect of some local antimalarial herbs on reproductive functions of male albino Wistar rat show that extract of Cylicodiscus gabunensis, Nauclea latifolia and Araliposis soyauxii significantly reduce testosterone concentration. ${ }^{11}$ Though anti-reproductive effects of some anti-malarial drugs have been reported following their administration to experimental animals, studies on humans have not corroborated same. ${ }^{12}$ Often, people in rural communities use antimalarial herbal therapies alone or before/after the use of conventional antimalarial drugs especially in West Africa. ${ }^{13}$

One of such herbal remedies for malaria used in the South-Eastern region of Nigeria is Hippocratea africana root bark extract. The plant has been reported to have a rich array of phytochemicals including alkaloids, tannins, cardiac glycosides, anthraquinonones and flavonoids ${ }^{14}$ which makes it a medicinally relevant. Hippocratea africana have been extensively studied. Its effect on some biochemical indices, lipid profile, comparative hepatic effect and antidiarrhoeal and antiulcer activities have been reported. ${ }^{2,14,15,16}$ Despite its reported promising antimalarial property and favourable effects on biochemical parameters, its effects on reproductive indices have not been reported. This study is designed to evaluate the testosterone concentration and testicular histomorphological changes following its administration on male albino Wistar rats. 


\subsection{Plant Material and Extraction}

\section{Materials And Methods}

Fresh root bark of Hippocratea africana was collected from Afaha Etok forest in Ibesikpo-Asutan Local Government Area of Akwa Ibom State. The plant was identified and authenticated by a taxonomist in the Department of Botany, University of Uyo, Uyo.

The fresh roots of Hippocratea africana were washed gently with tap water to remove sand, scrapped to remove the bark, cut into pieces and air-dried for two weeks. The air-dried sample was pulverized using manual grinder. $2 \mathrm{~kg}$ of the pulverized sample was macerated in $80 \%$ ethanol (sigma Aldrich) and allow to stand for 72 hours for the solvent to solubilized the active ingredients. The clear orange filtrate obtained was carefully siphoned off the residue using a tube and concentrated in a water bath at $45^{\circ} \mathrm{C}$ to obtain a crude extract.

\subsection{Animals and Experimental Design}

Twenty-four (24) matured male albino Wistar rats weighing between $100-160 \mathrm{~g}$ were obtained from the Animal House, Department of Pharmacology and Toxicology, Faculty of Pharmacy, University of Uyo. The animals were selected randomly into four groups of six rats per group. They were housed in a ventilated room in standard cages under standard laboratory conditions. The animals were fed grower rat chow and allowed water ad libitum.

Group I animals served as the control group and were administered $1 \mathrm{ml}$ of distilled water. Group II, III, and IV were the test groups and were administered 100, 200 and $300 \mathrm{mg} / \mathrm{kg}$ body weight of Hippocratea africana root bark extract respectively orally using a cannula attached to syringe for 14 days.

At the end of the treatment period, the rats were fasted overnight but still had water ad libitum. They were chloroform anaesthetized and dissected. Blood was collected through cardiac puncture using sterile syringe and needle into EDTA bottled. The whole blood was centrifuged using an MSE top centrifuge at $4000 \mathrm{rpm}$ for 10 minutes to obtain the serum used for the biochemical assay. The testes were harvested and preserved in $10 \%$ buffered formaldehyde prior to histological evaluation.

\subsection{Biochemical Analysis}

The serum testosterone was determined using testosterone Elisa kit for the quantitative determination of testosterone concentrations in rat serum. The rat testosterone Elisa kit (catalog 80550) is a solid phase enzyme-linked immunosorbent assay based on the principle of competitive binding as described by Marcus et al, (1985). ${ }^{17}$

\subsection{Histological Observations}

Sections from the testes were fixed with $10 \%$ buffered formalin, embedded with paraffin. After routine processing, paraffin sections of each tissue were cut into $5 \mu \mathrm{m}$ thickness and stained with haematoxylin and eosin (Drury and Wallington, 1967). ${ }^{18}$ The photomicrographs were taken with a digital camera (Canon Powershot A520) attached to a light microscope (Leitz Wetzlar, Germany)

\subsection{Ethical Clearance}

Ethical clearance for the animal study was obtained from Ethical and Research Committee of the Faculty of Basic Medical Sciences, University of Uyo. Uyo.

\subsection{Statistical Analysis}

All the results are presented as mean \pm standard deviation (SD). One-way analysis of variance (ANOVA) was employed for comparison to assess statistical significance using widows SPSS. Pairwise comparison was done using Student's t- test. Values of $\mathrm{P}<0.05$ were considered significant.

\section{Results}

The result of testosterone concentrations of mature male albino Wistar rats exposed to Hippocratea africana (root bark) is presented in Table I. Group I animals served as the control and were administered $1 \mathrm{ml}$ distilled water. Test Groups II, III and IV were administered 100, 200 and $300 \mathrm{mg} / \mathrm{kg}$ body weight of Hippocratea africana root bark extract respectively. The result showed a dose dependent significant $(P<0.05)$ increase in the concentration of testosterone compared with the control. There was slight non-significant $(P>$ 0.05) dose dependent increase in the weight of the testes compared with the control (Table II). The photomicrograph of the testes showed no evidence of pathology (Figure I). There were no abnormalities detected on the lumen of the seminiferous tubules (ST), spermatozoa (SZ), primary spermatocyte (PS) the lamina propria and basement membrane (BM) as well as interstitial cells of Leydig (ICL) in the test groups' animals appeared normal compared with the control.

Table I: Testosterone concentration and weight of testes of albino Wistar rats administered root bark extract of 
Testosterone Concentration and Testicular Histomorphology of Rats Exposed To Hippocratea ..

\begin{tabular}{|c|c|c|c|c|}
\hline \multicolumn{5}{|c|}{ Hippocratea africana } \\
\hline \multicolumn{4}{|c|}{ DOSAGE } & \multirow[b]{2}{*}{ PARAMETERS } \\
\hline $\begin{array}{c}300 \mathrm{mg} / \mathrm{kg} \mathrm{BW} \text { of } \\
H . A\end{array}$ & $\begin{array}{c}200 \mathrm{mg} / \mathrm{kg} \mathrm{BW} \text { of } \\
H . A\end{array}$ & $\begin{array}{c}100 \mathrm{mg} / \mathrm{kg} \mathrm{BW} \text { of } \\
H . A\end{array}$ & Control (1 ml water) & \\
\hline $16 \pm 1.14^{\mathrm{a},}$ & $12 \pm 0.89^{\mathrm{a}}$ & $11.42 \pm 0.74^{\mathrm{a}}$ & $8.33 \pm 1.72$ & TESTOSTERONE (mg/mL) \\
\hline $2.22 \pm 0.18$ & $2.21 \pm 0.22$ & $2.08 \pm 0.03$ & $1.81 \pm 0.70$ & WEIGHT OF TESTES (g) \\
\hline
\end{tabular}

Data presented as mean \pm standard deviation (SD)

$\mathrm{a}=$ significant different when compared to Group 1(control) at $P<0.05$

$\mathrm{BW}=$ Body weight;

H.A = Hippocratea africana

I

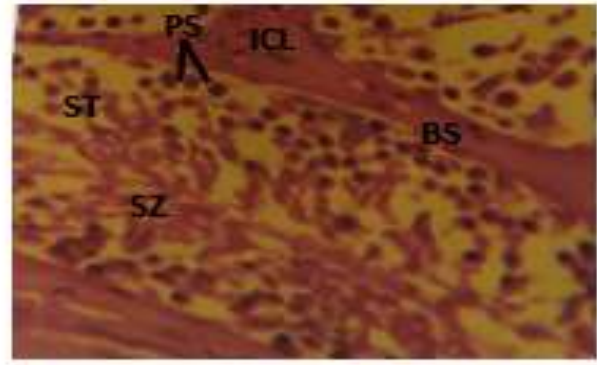

III

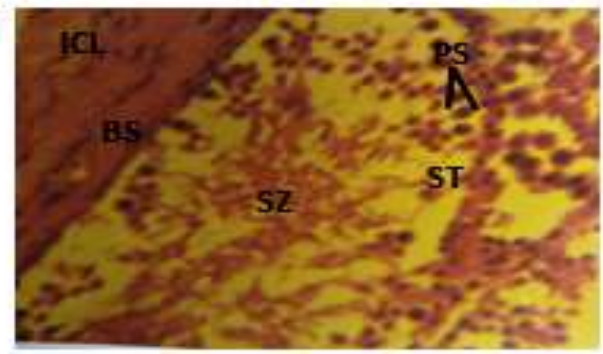

II

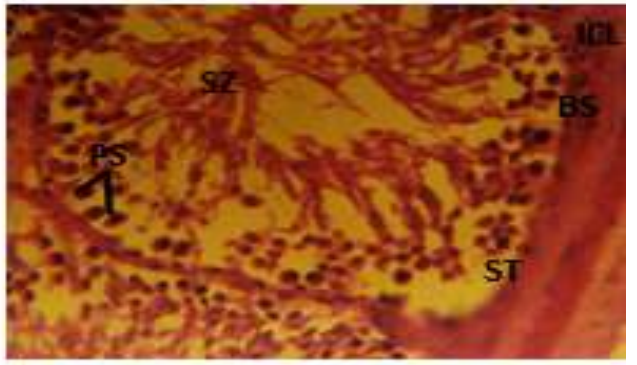

IV

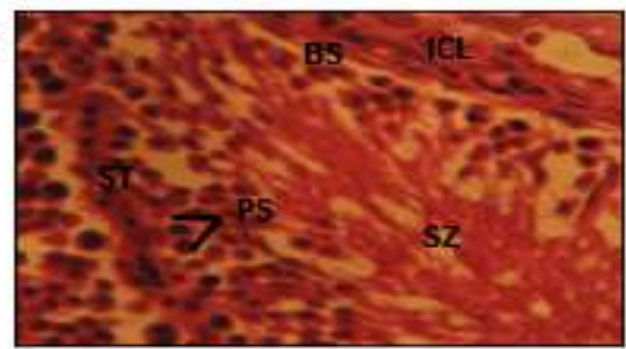

Figure I: Photomicrographs of testes of albino Wistar rats administered root bark extract of Hippocratea africana. Plate I (Group 1 - Control); Plate II (Group II - $100 \mathrm{mg} / \mathrm{kg}$ body weight H. A); Plate III (Group III $200 \mathrm{mg} / \mathrm{kg}$ body weight H.A); Plate IV (Group IV - $300 \mathrm{mg} / \mathrm{kg}$ body weight H.A). (Mag. X 400)

\section{Discussion}

Testosterone is a naturally occurring steroid hormone, made primarily by the testicles in males. It is the main sex hormone and plays an important role in the development of the male reproductive system. Levels of testosterone are typically more than five times higher in adult male than female. ${ }^{19}$

In this study, there was a dose dependent significant $(\mathrm{P}<0.05)$ increase following the administration of Hippocratea africana root bark extract to male albino Wistar rats. Reproductive functions are controlled by complex interactions that involve hormones and the reproductive organs. These relationships are important in spermatogenesis, sperm development, maturation and sexual performance. ${ }^{20}$ Testosterone is needed for growth and acts in the seminiferous tubules to initiate and maintain spermatogenesis in association with follicle stimulating hormones. ${ }^{21}$ The dose dependent increase in the concentration of testosterone exhibited by Hippocratea africana implies that the herb supports testicular steroidogenesis. Olorunshola and Baa, 2014 reported a normal testosterone concentration in a study comparing the effect of antimalarials (quininine, artemether and fansidar) on some reproductive organs and serum testosterone levels in male Wistar rats ${ }^{22}$. A study on the effect of short term administration of artemether-lumefantriene on testicular function and antioxidant defense in rats showed that there was no significant impact on the testosterone level. ${ }^{20} \mathrm{In}$ another study, testosterone concentration was reported to be significantly low in treatment involving the antimalarials, Lonart and Chloroquine and significantly increased with Fansidar and Coartem, showing that low or high levels of testosterone with antimalarial drugs are drug dependent. ${ }^{23}$

The histology of the testes in this study further corroborates the increased testosterone concentration induced by the herb. The histological results suggest that $H$. africana did not cause degeneration in the rat testes as seen in the normal lumen of the seminiferous tubules, lamina propria, basement membrane and interstitial cells of Leydig of the test groups' animals, implying that the herb did not permeate the blood- testes barrier and thus did not affect spermatogenesis. It also suggests that there was no reduction of viable sperms, inferring that the herb does not affect fertility. The present of spermatozoa (the specific output of the testes that fertilizes the mature ovum in sexual reproduction) and spermatocytes (the primary cells of the testes that gives rise to 
Testosterone Concentration and Testicular Histomorphology of Rats Exposed To Hippocratea ..

spermatozoa) which are produced and found in the seminiferous tubules of the testes respectively in all the test groups' animal's histological sections further shows that the did not permeate the blood- testes barrier. Olumide and Raji however, reported visible lesions degenerative changes of testis and epididymis of rats treated with artesunate. The testicular histology showed degeneration of the plasmalemma with vacuolization of the seminiferous tububules. Izunya et al also reports deleterious effect on the histology of the testis following administration of normal dose of artesunate to rats. The result suggested that artesunate could be a potential male antiferftility agent. ${ }^{24}$

Our result also shows that there was slight increase in testes weight in a dose dependent manner which further infers the increased concentration of testosterone exhibited by the herb. Weight of male reproductive organ is a useful indicator for assessing reproductive risk in experimental animals ${ }^{9}$ and change in weight or absolute weight of organ after administration of drug is an indication of drug toxicity. ${ }^{25}$, ${ }^{26}$ Also, spermatogenesis can be assessed primarily by testicular size. This is because the tubules and germinal elements accounts for approximately $98 \%$ of the testicular weight. ${ }^{27}$ The observed increase in weight of the testis in this study implies that the herb did not cause degeneration of tubules and loss of germinal elements. The herb has been reported to possess rich array of phytochemicals which may be responsible for the improved steroidogenesis observed in this study ${ }^{14}$. Antioxidant activities of plant extracts have been suggested to be responsible for improved fertility in male rats. ${ }^{28}$ Olorunshola and Baa, however reported decreased weight of testes following administration of quinine and artemether to experimental rats. ${ }^{22}$ Okanlawon and Ashiru also reported significantly reduced body and organ weights following administration of chloroquin to rats for 7 weeks. ${ }^{29}$

In conclusion, Hippocratea africana has no negative effect on the testosterone concentration and the testicular morphology. The raised testosterone concentration suggests that, it possesses androgenic effect implying that the herb may have induced the gonads to bring about spermatogenesis. The favorable androgenic property and no morphological changes on the testes as well as increase weight of the testes following administration of the herb to experimental animals further promote it for anti-malarial therapy. Study on its effect on female reproductive indices is suggested to corroborate these findings.

\section{References}

[1]. World Health Organization - WHO. Guidelines for the treatment of Malaria. 2nd ed. Geneva: WHO 2010.

[2]. Ndem, J.I.; Eteng, M.U.; Akpanabiatu, M.I.; Uwah, A.; Otitoju, O.; Akpanyung, E.O. Effect of Hippocratea africana Root Bark Extract on Biochemical Indices of Male and Female Albino Wistar Rats. Journal of Pharmacognosy and Phytotherapy, 5(4), 2013, 72-76.

[3]. Obianime, A.W.; Aprioku, J.S. Comparative Study of Artesunate, ACTs and their Combinants on the Spermatic Parameters of Male Guinea Pig. Niger J Physiol Sci, 24(1), 2009, 1-6.

[4]. Djimbe, A.; Doumbo. O.; Cortese, J.; Kayentoa, K.; Diourte, Y.; Dicko, A.; Su, X.; Nomura, T.; Fidock, D.; Wellems, T.; Plowe, C. Coulibaly D. A Molecular Marker for Chloroquine-Resistant Falciparum Malaria. New England Journal of Medicine, 344(4), 2001, 299-302.

[5]. Rates, S.M. Plants as Source of Drugs. Toxicon, 39(5), 2011, 603-613.

[6]. Taylor, W.R.; White, N.J. Antimalarial Drug Toxicity: A Review. Drug Safety, 27(1), 2004, 25-61.

[7]. Olumide, S.A.; Raji, Y. Long Term Administration of Artesunate Induces Reproductive Toxicity in Male Rats. J Reprod Infertile, 12(2), 2011, 249-260.

[8]. Kareem, F.A.; Osonuga, I.O.; Akindele, R.A.; Kukoyi, B.I.; Taiwo, E.O.; Inegbeneboh, D. Antifertility Effect of P-Alaxin in Male Adult Wistar Rats. Journal of Natural Science Research, 5(9), 2015, 5-8.

[9]. Raji, Y.; Osonuga, I.; Akinsomisoye, O.; Mewoyeka, O. Evaluation of Oral Artemisinin Derivatives in Male Rats. Medical Science, 5(4), 2005, 303-306.

[10]. Adeeko, A.; Dada, O. Chloroquine Reduces Fertilizing Capacity of Epididyma Sperm in Rats. Medical sciences, 27(1-2), 1998, 634.

[11]. Ikpeme, E.V.; Ekaluo, U.B.; Udensi, O.U.; Ekerette, E.E. Potential Effect of some Local Antimalarial Herbs on Reproductive Functions of Male Albino Rat. Annual Review and Research in Biology, 3(4), 2013, 742-751.

[12]. Ejebe, D.E.; Ojieh. A.E.; Ovuakporaye, S.I.; Odion-Obomhense, H.K.; Adegor, E.C.; Amadi, C.N.; Nwadito, C.; Emudainohwo, J.O.T.; Ozoko, T.C. Effects of Antimalarial Alkaloids on the Sperm Properties and Blood Levels of Reproductive Hormones of Adult Men. African Journal of Biotechnology, 7(19), 2008, 3395-3400.

[13]. Steve, O.I.; Joseph, M.A.; Cyprian, O.; Clement, O. Chemotherapeutic Interaction between Khaya grandifoliola Stem Bark Extract and two Antimalarial Drugs in Mice. African Journal of Traditional, Complementary and Alternative Medicines, 7(4), 2010, 370376.

[14]. Ndem, J.I.; Eteng, M.U.; Uwah, A.F. Effect of Hippocratea africana Root Bark Extract on Lipid Profile of Female and Male Albino Wistar Rats. Journal of Scientific Research and Reports, 3(19), 2014, 2574-2583.

[15]. Ndem, J.I.; Ewere, E.G. Comparative Hepatic Effect of Hippocratea africana Root Bark Extract on Female and Male Albino Wistar Rats. British Journal of Pharmaceutical Research, 9(3), 2015, 1-11.

[16]. Okokon, J.E.; Akpan, H.D.; Umoh, E.E.; Ekaidem, I.S. Antidiarrhoeal and Antiulcer Activities of Hippocratea africana Root Extract. Pakistan Journal of Pharmaceutical Sciences, 24(3), 2011, 201-205.

[17]. Marcus, G.J.; Durnford, R.A. Simple Enzyme-Linked Immunosorbent Assay for Testosterone. Steroids, 46(6), 1985, 975-986.

[18]. Drury, R.A.; Wallington, A. Carleton's Histological Techniques, $4^{\text {th }}$ edition, 1967. P. 214-215.

[19]. Burtis, A.; Ashwood, E.; Bruns, E.; Tietz Textbook of Clinical Chemistry and Molecular Diagnostics (5 ${ }^{\text {th }}$ edition). Elsevier Health Science. 1975.

[20]. Morakinyo, A.O.; Oludare, G.O.; Ojulari, S.; Afolabi, A.O. Effect of Short Term Administration of Artemether-Lumefantrine on Testicular Functions and Antioxidant Defense in the Rat. Research Journal of Medicine and Medical Sciences, 4(2), 2009, 165-170. 
[21]. Christensen, A.C. Leydig Cells. In: Handbook of Physiology, Edited by P.O. Greep and E.B. Astwood. Washington D.C. American Physiological Society. 1975, Pp. 167-172.

[22]. Olorunshola, K.V.; Baa, Y. Comparative Effect of three Antimalarials (Quinine, Artemether and Fansidar) on some Reproductive Organs and Serum Testosterone Level in Male Albino Wistar Rats. Br J Pharmacology Toxicol, 5(2), 2013, 2013, 55-58.

[23]. Jimmy, E. O.; Mbee, J. N.Testosterone levels in coartem, chloroquine. fansidar and lonart regulated by cholesterol. North American Open Physiology Research Journal,1(1), 2014, 1-9.

[24]. Izunya, A.M.; Nwaopara1, A.O.; Aigbiremolen, A.E.; Odike, M. A.C.; GA Oaikhena, G. A.; JK Bankole, J.K. Biology and Medicine, 2(2), 2010, 49-56,

[25]. Simmons, J.E.; Yang, R S.; Berman, E. Evaluation of the nephrotoxicity of complex mixtures containing organics and metals: advantages and disadvantages of the use of real-world complex mixtures. Environ Health Perspect. 103(1), 1995, 67-71.

[26]. Maina, M.B.; Garba, S.H.; Jacks, T.W. Histological evaluation of the rat's testis following administration of an herbal tea mixture. J Pharmacol Toxicol. 3, 2008, 464-70.

[27]. Sherines, R.J.; Howards, S.S. Male fertility. In: Har-rison JH, Gittes RF, Perimutter AD, Stamey TA, Walsh PC, editors. Campbell's Urology. Philadelphia: Saunders WB. Co; 1987. p. 715.

[28]. Heydari, N.M.; Aboutalebi, H.; Naseri, M. Effect of Fumari parviflora alcohol extract on male rat reproductive System. $J$ Med Plants Res, 10, 2012, 2004-2010.

[29]. Okanlawon, A.O.; Ashiru, O.A. Sterological estimation of seminiferous tubular dysfunction in chloroquine treated rats. Afr J Med Med Sci.27(1-2), 1998, 101-6. 